\title{
埋深和播种密度对豚草种子出苗及幼苗生长的影响
}

\author{
熊韧琦 ${ }^{1}$, 赵彩云 ${ }^{1, *}$, 赵相健 ${ }^{2}$ \\ 1 中国环境科学研究院, 北京 100012 \\ 2 中国合格评定国家认可中心, 北京 100062
}

\begin{abstract}
摘要: 豚草是一种全球性的恶性人侵杂草,给我国生物多样性及经济发展造成了巨大威胁。为研究豚草种子出苗和幼苗生长的 影响因素, 采用盆栽实验分析了种子大小 $(\mathrm{L} 、 \mathrm{M} 、 \mathrm{~S})$ 与埋深 $(2 、 4 \mathrm{~cm}$ 和 $6 \mathrm{~cm}$ ) 或播种密度 $(2 、 4$ 粒/盆和 8 粒/盆) 对豚草(Ambrosia artemisiifolia) 种子的出苗和幼苗生长的影响。研究结果表明,埋深对豚草种子出苗的影响高于播种密度及种子大小的影响,较 浅的埋深有利于豚草种子出苗; 出苗率在不同播种密度下均具有较高水平,达到 $67.9 \%$ - $100 \%$,这种高出苗率是豚草在不同生 境成功定植的原因之一。豚草的幼苗生长受埋深或播种密度的影响大于种子大小的影响, 且小种子更易受埋深或播种密度的 影响。种子大小显著影响豚草幼苗的株高和基径 $(P<0.05)$, 总体上较大种子的株高和基径高于小种子, 此外更小的种子会将 生物量更多的分配给根以促进幼苗的生长。幼苗的株高和基径在较浅的埋深下更高,而豚草幼苗的单株生物量、单株地上和地 下生物量随埋深的增加而增加。播种密度的增加会加剧豚草幼苗之间对水分、营养、光照等资源的竞争, 导致其单株地上、地下 及总生物量显著降低 $(P<0.05)$ 。研究发现豚草在浅埋深、低密度生境中更容易人侵成功, 因此可以通过对土壤进行深翻, 采取 替代控制, 种植竞争能力强的本地植物等手段有效管理和防治豚草。
\end{abstract}

关键词: 种子大小; 出苗;幼苗;豚草

\section{Effects of burial depth and planting density on seedling emergence and growth of Ambrosia artemisiifolia of different seed sizes}

\author{
XIONG Yunqi ${ }^{1}$, ZHAO Caiyun ${ }^{1, *}$, ZHAO Xiangjian ${ }^{2}$ \\ 1 Chinese Research Academy of Environmental Sciences, Beijing 100012, China \\ 2 China National Accreditation Service for Conformity Assessment, Beijing 100062, China
}

\begin{abstract}
Ambrosia artemisiifolia, native to North America, is a notorious invasive plant worldwide. It has posed a serious threat to the biodiversity, stability of ecosystem, economic development and human health in China. Research on the seeding emergence and growth process of A. artemisiifolia, which are important stages in its life history, is essential for invasive management. However, little attention has been paid to the effects of seed characteristics, sowing depth and density at the emergence and growth stages of A. artemisiifolia. In order to study the influence factors of seed emergence and seedling growth of $A$. artemisiifolia, we conducted a pot experiment to examine the effects of seed size ( L, M, S) and burial depth $(2,4$ and $6 \mathrm{~cm})$ or planting density $(2,4$ and 8 seeds per pot) on the emergence and seedling growth of $A$. artemisiifolia. It was found that the effect of burial depth on the emergence of $A$. artemisiifolia was much stronger than that of planting density and seed size, and we also found that the shallower burial depth promoted the emergence of seeds. Under the three different planting densities, A. artemisiifolia showed a relatively high emergence rate at about $67.9 \%-100 \%$, which was one of the reasons why $A$. artemisiifolia could successfully colonize in different habitats. The seedling growth was
\end{abstract}

基金项目: 国家重点研发计划项目(2016YFC1201100) ; 生物多样性调查评估项目(2019HJ2096001006)

收稿日期: 2021-03-08; 采用日期:2021-07-16

* 通讯作者 Corresponding author.E-mail: zhaocy@ craes.org.cn 
more affected by burial depth and planting density than seed size, and small seeds were more susceptible to the effects of burial depth and planting density. The seedling height and basal diameter were affected by seed size significantly $(P<0$. 05 ). In general, the seedling height and basal diameter of larger seeds were higher than those of small seeds. In addition, smaller seeds would distribute more biomass to the roots to promote the growth of seedlings. The seedling height and basal diameter were higher at shallower burial depth, while the total individual biomass, individual aboveground and underground biomass increased with the increase of burial depth. As planting density increased, the intraspecific competition of seedlings for water, nutrition, light and other resources increased, resulting in a significant decrease in the aboveground, underground and total biomass of individual $(P<0.05)$. In this study, we found that $A$. artemisiifolia was more inclined to invade habitats with shallow burial depth and low density successfully. Therefore, for the purpose of preventing $A$. artemisiifolia invasion, deep ploughing and replacement control technology, which use competitive native plants to compete with invasive plants, can be conducted to inhibit the growth of A. artemisiifolia in China.

Key Words: seed size; emergence; seedling; Ambrosia artemisiifolia

外来人侵植物是指从其原生范围迁移到新的生境, 并对该地区生物多样性、生态系统结构功能、农林牧渔 业生产和人类健康造成严重威胁的植物 ${ }^{[1]}$ 。种子出苗和幼苗生长是植物生活史中最敏感也是最重要的阶 段, 影响着植物种群增长、扩散和延续 ${ }^{[2]}$, 是人侵植物成功定植的关键时期 ${ }^{[3]}$, 同时受到自身内在因素和外界 环境因素的影响。影响种子萌发和幼苗生长的内在因素主要包括种子大小、种子活力、种子成熟度以及种子 是否休眠等 ${ }^{[4]}$ 。其中种子大小是最重要的性状, 影响种子萌发、幼苗的建成、个体适合度以及群落更新等过 程 ${ }^{[5-6]}$ 。研究发现较小的种子更易扩散, 并且更能保持种子库的持久性 ${ }^{[7-8]}$; 而较大的种子更能抵抗环境压 力, 竞争能力更强 ${ }^{[9]}$ 。因此, 对外来人侵植物而言, 种子大小严重影响了其传播扩散, 以及与本地物种的 竞争。

适宜的光照、水分、温度和氧气等是种子出苗的必要环境条件。在一定的埋深范围内,覆土可以给种子提 供更适宜的环境条件, 如温度、湿度等 ${ }^{[10]}$, 还可以避免动物的取食 ${ }^{[11]}$, 从而有利于种子萌发、幼苗出苗及生 长。但是埋深过深会抑制幼苗的出苗和存活, 因为深埋条件下, 种子由于缺乏氧气、光照和温度变化而难以萌 发, 同时幼苗到达土壤表面的能量需求和时间增加, 使得出苗前死亡率增加 ${ }^{[12-13]}$ 。密度是自然界重要的选择 压力之一, 播种密度会影响可获得性资源的数量, 使得植株间产生竞争, 影响植物个体生物量和存活率 ${ }^{[14-15]}$ 。 研究表明, 播种密度与人侵植物定殖呈正相关关系, 因为高密度的人侵物种会引起资源竞争而排斥本地 物种 ${ }^{[16-17] 。}$

豚草 (Ambrosia artemisiifolia), 又名艾叶破布草或豕草, 属双子叶植物纲菊科豚草属一年生草本植物, 原 产于北美, 是一种被世界公认的恶性人侵杂草 ${ }^{[18-19]}$ 。豚草严重影响了人侵地的生物多样性以及生态系统稳 定性, 给农业、渔业和牧业等带来巨大经济损失, 其致过敏的花粉对公共卫生也造成极大影响, 已被列人我国 首批人侵物种名单 ${ }^{[20-21]}$ 。为加强对该人侵物种的控制和管理, 对其生活史重要阶段的种子出苗和幼苗生长 过程的研究至关重要。目前, 国内外对豚草的研究主要集中于豚草的人侵机制 ${ }^{[22-25]}$ 、分布和扩散 ${ }^{[26-28]}$ 、对环 境因子的响应 ${ }^{[20,29-31]}$ 、危害与防治 ${ }^{[21,32]}$ 等方面, 而鲜少关注豚草出苗和幼苗生长阶段受种子特征、播种深度 和密度的影响。外来植物在幼苗阶段的适应性直接影响了其成功人侵的可能性 ${ }^{[33]}$, 因此, 本文以豚草为研究 对象, 采用盆栽实验, 研究了种子大小和埋深/播种密度对豚草种子的出苗和幼苗生长的影响, 进而为豚草的 防控和管理提供科学依据。

\section{1 材料与方法}

1.1 实验地点

实验于 2014 年 4-6 月份在北京中国环境科学研究院顺义基地进行, 该地区属于温带大陆性半湿润季风 
气候, 年均气温 $11.5^{\circ} \mathrm{C}$, 年均降雨量约 $610 \mathrm{~mm}, 80 \%$ 降水集中于 7-8 月, 年日照 $2750 \mathrm{~h}$, 年无霜期约为 $195 \mathrm{~d}^{[34]}$ 。

\section{2 实验材料}

豚草种子于 2013 年收集自顺义基地种植的豚草植株, 从生长健壮的植株上摘取不同大小的成熟种子晾 晒后置于 $4^{\circ} \mathrm{C}$ 的干燥条件下保存。实验开始前, 分别用 10 目、12 目和 14 目的土壤篎( 孔径分别为 $2.00 、 1.66$ $\mathrm{mm}$ 和 $1.43 \mathrm{~mm}$ ) 将豚草种子按大小分为三组: 大 $(2.00 \mathrm{~mm}>d \geqslant 1.66 \mathrm{~mm}, \mathrm{~L})$ 、中 $(1.66 \mathrm{~mm}>d \geqslant 1.43 \mathrm{~mm}, \mathrm{M})$ 和 小 $(1.43 \mathrm{~mm}>d, \mathrm{~S})$ 。

\section{3 研究方法}

\subsection{1 实验设计}

埋深实验设置 3 个种子大小 $(\mathrm{L} 、 \mathrm{M} 、 \mathrm{~S})$ 和 3 个埋深处理 $(2 、 4 \mathrm{~cm}$ 和 $6 \mathrm{~cm})$, 每个处理 9 个重复。2014 年 4 月 21 日进行播种, 取高 $27 \mathrm{~cm}$ 、内径 $31 \mathrm{~cm}$ 、地径 $18 \mathrm{~cm}$ 的塑料花盆 81 个,平均分为 3 组 (每组 27 个) 分别播种 大、中和小种子; 再将每组的 27 个花盆按 9 盆 1 组分为 3 组, 分别对应 3 个不同埋深处理 $(2 、 4 \mathrm{~cm}$ 和 $6 \mathrm{~cm})$ 。 播种时,花盆中先填人部分培养基质,充分浇水后放人豚草种子, 再分别铺上厚约 $2 、 4$ 或 $6 \mathrm{~cm}$ 的湿润土壤以 实现不同埋深处理。每个花盆播种 10 粒同大小等级的豚草种子,试验用种子总计: 3 种子大小 $\times 3$ 埋深处理 $\times$ 9 重复 $\times 10$ 粒 $=810$ 粒, 培养基质为去除表面调落物的 $0-25 \mathrm{~cm}$ 农田土与腐殖土 $2: 1$ 混合。

播种密度实验设置 3 个种子大小 $(L 、 M 、 S)$ 和 3 个播种密度处理 (每盆 $2 、 4$ 粒和 8 粒), 每个处理 4 个重 复。 2014 年 4 月 15 日进行播种, 取高 $27 \mathrm{~cm}$ 、内径 $31 \mathrm{~cm}$ 、地径 $18 \mathrm{~cm}$ 的塑料花盆 36 个,平均分为 4 组 (每组 12 个) 分别播种大、中和小种子; 再将每组的 12 个花盆按 4 盆 1 组分为 3 组, 分别对应 3 个不同播种密度处理 (每盆 $2 、 4 、 8$ 粒)。播种时,花盆中先填人部分培养基质,充分浇水后每盆放人 $2 、 4$ 或 8 粒豚草种子,再填人约 $2 \mathrm{~cm}$ 厚的湿润土壤覆盖种子, 培养基质为去除表面调落物的 $0-25 \mathrm{~cm}$ 农田土与腐殖土 $2: 1$ 混合。试验用种 子总计: 3 种子大小 $\times 4$ 重复 $\times(2$ 粒 +4 粒 +8 粒 $)=168$ 粒。

\subsection{2 生长特征记录}

两个实验均分别进行了 $50 \mathrm{~d}$, 播种后每天浇水保持土壤湿润,看见子叶则视为出苗。第 50 天记录每个花 盆的豚草植株数目并进行收获, 收获前分别用直尺和游标卡尺测量每株豚草幼苗的株高、基径, 然后将植株挖 出洗净后用直尺测量根长, 随后将植株地上和地下部分分开后置于 $80^{\circ} \mathrm{C}$ 烘干 $48 \mathrm{~h}$, 用千分之一天平称重。

本实验记录了幼苗数、株高、根长、基茎、每盆总地上生物量和每盆总地下生物量; 并计算出苗率( 出苗数 量/播种数量)、每盆平均株高、每盆平均根长、每盆平均基径、每盆总生物量 (每盆总地上生物量 + 每盆总地下 生物量)、单株生物量 (每盆总生物量/出苗数量)、单株地上生物量 (每盆总地上生物量/出苗数量)、单株地下 生物量 (每盆总地下生物量/出苗数量) 以及根冠比(每盆总地下生物量/每盆总地上生物量)。

\section{4 数据分析}

先将相关数据进行对数转换 $(y=\lg (x+1))$, 然后采用一般线性模型进行双因素方差分析 (Two-way ANOVA) 检验种子大小和埋深/播种密度及其相互作用对种子萌发和幼苗生长的影响。如若差异显著, 则采 用 Duncan 多重比较检验每个处理的差异性 $(\alpha=0.05)$ 。所有数据采用 Excel 2016 进行统计, SPSS 25.0 进行 分析处理。

\section{2 结果与分析}

2.1 种子大小和埋深对豚草种子出苗和幼苗生长的影响

种子大小对豚草的株高影响显著 $(P<0.05)$, 对基径的影响极显著 $(P<0.01)$; 除株高和根长外, 埋深对其 他指标均有极显著影响 $(P<0.01)$; 种子大小和埋深的交互作用仅对基径的影响达到显著水平 $(P<0.05)$ 。 (表 1)。 
表 1 种子大小和埋深对豚草种子出苗和幼苗生长影响的双因素方差分析

Table 1 Two-way ANOVA of effects of seed size and burial depth on seed germination and seedling growth of A. artemisiifolia

\begin{tabular}{|c|c|c|c|c|c|c|}
\hline \multirow{2}{*}{ 指标 Index } & \multicolumn{2}{|c|}{ 种子大小 Seed size } & \multicolumn{2}{|c|}{ 埋深 Depth } & \multicolumn{2}{|c|}{ 种子大小×埋深 Seed size×Depth } \\
\hline & $F$ & $P$ & $F$ & $P$ & $F$ & $P$ \\
\hline 出苗率 Seedling ratio & 1.716 & 0.187 & 77.999 & $<0.001$ & 1.093 & 0.367 \\
\hline 株高 Plant height & 4.507 & 0.016 & 3.160 & 0.051 & 2.293 & 0.072 \\
\hline 根长 Root length & 2.319 & 0.109 & 0.048 & 0.953 & 0.241 & 0.914 \\
\hline 基径* Basal stem & 5.631 & 0.006 & 7.190 & 0.002 & 2.604 & 0.046 \\
\hline 盆总生物量 * Total biomass per pot & 2.305 & 0.110 & 8.373 & 0.001 & 0.734 & 0.573 \\
\hline 单株地上生物量" Aboveground biomass & 0.912 & 0.408 & 15.383 & $<0.001$ & 0.416 & 0.796 \\
\hline 单株地下生物量 * Underground biomass & 0.692 & 0.505 & 16.720 & $<0.001$ & 1.196 & 0.323 \\
\hline 单株生物量 * Individual biomass & 0.508 & 0.605 & 17.398 & $<0.001$ & 0.538 & 0.708 \\
\hline 根冠比 Root-shoot ratio & 2.176 & 0.124 & 12.314 & $<0.001$ & 0.598 & 0.666 \\
\hline
\end{tabular}

*表示数据经过对数变换

所有大小种子的出苗率均在 $2 \mathrm{~cm}$ 时最大,达到 $47.8 \%-52.2 \%$, 并随埋深增加而显著下降; 不同大小种子 的出苗率在不同播种埋深间无显著差异。不同大小种子豚草的株高均在埋深 $2 \mathrm{~cm}$ 时最高,大、中种子的株高 在不同埋深间差异不显著,小种子的株高在埋深 $2 \mathrm{~cm}$ 时显著高于 $4 \mathrm{~cm}$ 时 $46.2 \%$ 。在埋深 $2 \mathrm{~cm}$ 和 $4 \mathrm{~cm}$ 时, 株 高随种子大小增加而逐渐增加, 而埋深 $6 \mathrm{~cm}$ 时, 中种子的株高最高; 其中埋深 $4 \mathrm{~cm}$ 时, 大种子的株高较小种 子显著增加了 1.25 倍,其余埋深处理下,豚草的株高在不同种子大小之间没有显著差异。不同大小种子的基 径在 $2 \mathrm{~cm}$ 埋深时最大,仅小种子的基径在不同埋深间差异显著,且埋深 $2 \mathrm{~cm}$ 时的基径显著大于埋深 $4 \mathrm{~cm}$ 时 1.6 倍; 除埋深 $4 \mathrm{~cm}$ 外,基径在不同大小种子间均无显著差异, 埋深 $4 \mathrm{~cm}$ 时, 基径随种子大小增加而显著增 加, 大种子的基径分别为中、小种子的 $1.63 、 2.97$ 倍(图 1)。

中种子的每盆总生物量在不同埋深间差异显著, 且埋深 $2 \mathrm{~cm}$ 时较埋深 $6 \mathrm{~cm}$ 时显著增加了 $26.3 \%$, 其余 大小种子的每盆总生物量在不同埋深间的差异未达到显著水平; 不同埋深下较大种子的每盆总生物量均最 大,其仅在埋深 $4 \mathrm{~cm}$ 时显著高于小种子 $39.0 \%$,其余埋深下不同种子大小间无显著差异。

随埋深增加所有大小种子的单株生物量、单株地上生物量和单株地下生物量均显著增加; 不同埋深处理 下,该 3 个指标在不同大小种子间没有显著差异。大种子的单株生物量和单株地上生物量在埋深 $6 \mathrm{~cm}$ 时分 别显著高于埋深 $2 \mathrm{~cm}$ 时 2.75 倍和 2.30 倍, 中、小种子的单株生物量和单株地上生物量在埋深 $6 \mathrm{~cm}$ 时分别比 埋深 $4 \mathrm{~cm}$ 时显著增加了 $1.48 、 1.06$ 倍和 $1.38 、 1.03$ 倍。大种子的单株地下生物量在不同埋深间差异不显著, 中、小种子的单株地下生物量在埋深 $6 \mathrm{~cm}$ 时分别比埋深 $4 \mathrm{~cm}$ 时显著增加了 1.58 倍和 1.08 倍(图 1)。

不同大小种子的根冠比均在埋深 $6 \mathrm{~cm}$ 时最大, 为 $0.80-1.01$, 其中小种子的根冠比随埋深增加而逐渐增 加, 且埋深 $6 \mathrm{~cm}$ 时显著高于埋深 $2 \mathrm{~cm}$ 时 $18.7 \%$, 其余大小种子根冠比在不同埋深间差异不显著。在 $4 \mathrm{~cm}$ 和 $6 \mathrm{~cm}$ 埋深下小种子的根冠比最大, 在 $2 \mathrm{~cm}$ 埋深下中种子的根冠比则最大, 不同大小种子间的根冠比差异仅 在埋深 $4 \mathrm{~cm}$ 时达到显著水平, 且小种子的根冠比显著高于大种子 $23.8 \%$ (图 1)。

2.2 种子大小和播种密度对豚草种子出苗和幼苗生长的影响

种子大小仅对出苗率具有显著影响 $(P<0.05)$, 对其余所有指标的影响均未达到显著水平 $(P>0.05)$; 播种 密度对豚草幼苗的每盆总生物量、单株地上和地下生物以及单株总生物量有极显著影响 $(P<0.01)$; 种子大小 和播种密度的交互作用对所有指标均无显著影响 $(P>0.05)$ ( 表 2)。

豚草种子在不同播种密度下均具有较高的出苗率, 达到 67.9\%-100\%, 且播种密度对不同大小种子的出 苗率无显著影响; 除播种密度为每盆 2 粒外, 出苗率受种子大小的影响不显著, 在每盆 2 粒的播种密度下, 出 苗率随种子大小增加而逐渐增加, 且大种子显著高于小种子 $36.8 \%$ (图 2)。

不同大小种子豚草的每盆总生物量均在播种密度为 8 粒每盆时最大, 其中大种子在播种密度为每盆 8 粒 

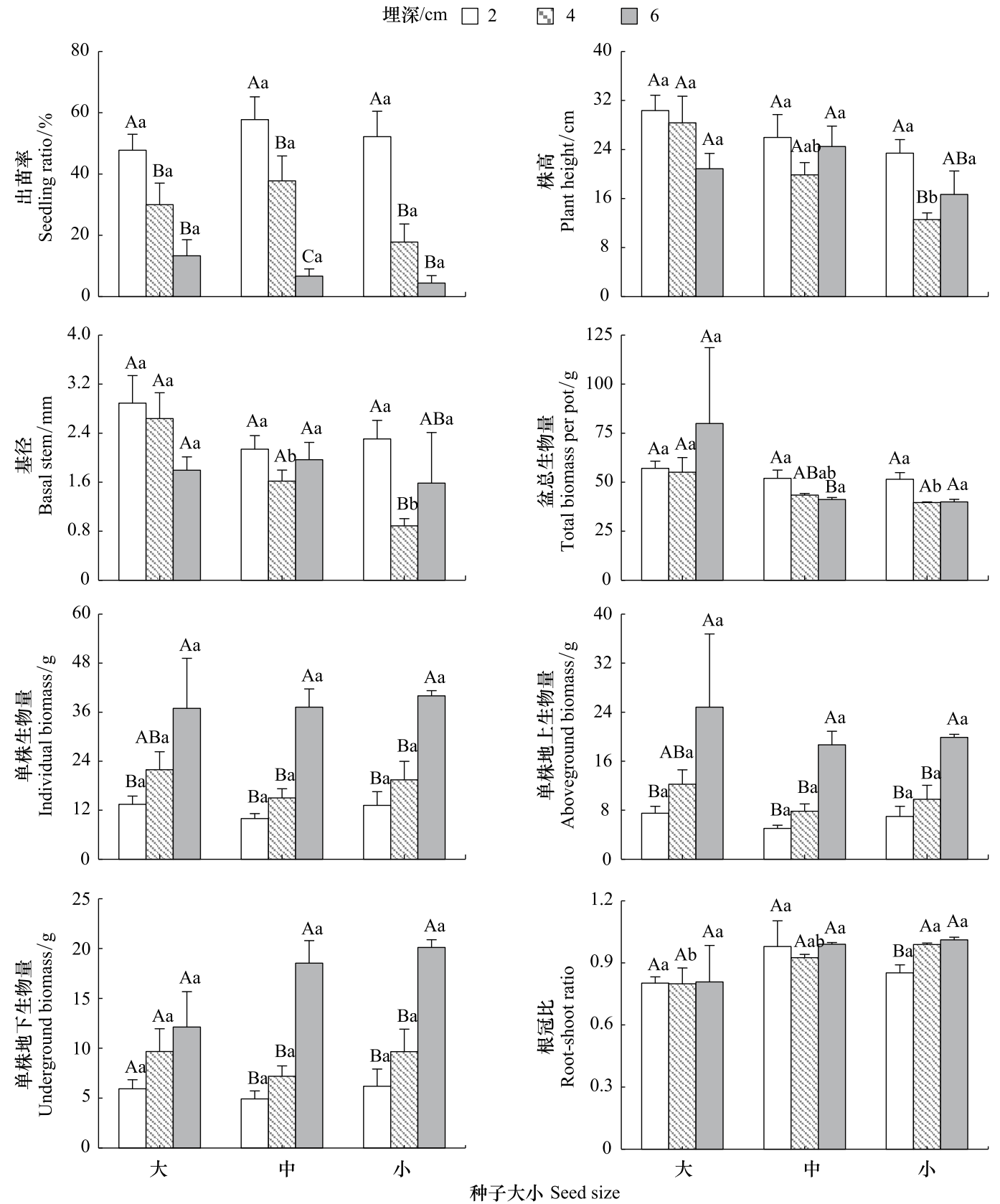

图 1 不同种子大小在不同埋深处理下各指标的差异

Fig.1 The difference of parameters among different seed size of A. artemisiifolia with different burial depth 不同大写字母和不同小写字母分别表示同一大小种子的不同埋深间以及同一埋深下不同大小种子间差异显著 $(P<0.05)$

时显著高于每盆 4 粒时 $16.3 \%$,中种子的每盆总生物量在不同播种密度之间无显著差异, 小种子的每盆生物 量在播种密度为每盆 8 粒时较每盆 2 粒时显著增加了 $9.9 \%$; 种子大小对不同播种密度下的盆总生物量没有 显著影响。所有大小种子的单株总生物量、单株地上生物量和单株地下生物量均随播种密度增加而显著降 低; 而种子大小对该 3 个指标的影响均未达到显著水平。其中,大、中、小种子在播种密度为每盆 2 粒时的单 株生物量较每盆 8 粒时分别显著增加了 2.19、2.42 倍和 2.91 倍; 单株地上生物量较每盆 8 粒时分别显著增加 了 $2.14 、 2.27$ 倍和 2.75 倍; 单株地下生物量较每盆 8 粒时分别显著增加了 $2.25 、 2.58$ 倍和 3.07 倍( 图 2)。 
表 2 种子大小和播种密度对豚草种子出苗和幼苗生长影响的双因素方差分析

Table 2 Two-way ANOVA of effects of seed size and planting density on seed germination and seedling growth of A. artemisiifolia

\begin{tabular}{|c|c|c|c|c|c|c|}
\hline \multirow{2}{*}{ 指标 Index } & \multicolumn{2}{|c|}{ 种子大小 Seed size } & \multicolumn{2}{|c|}{ 埋深 Depth } & \multicolumn{2}{|c|}{ 种子大小×埋深 Size×Depth } \\
\hline & $F$ & $P$ & $F$ & $P$ & $F$ & $P$ \\
\hline 出苗率” Seedling ratio & 3.328 & 0.043 & 0.240 & 0.787 & 0.744 & 0.566 \\
\hline 株高 Plant height & 0.897 & 0.414 & 2.507 & 0.090 & 1.582 & 0.190 \\
\hline 根长 Root length & 2.085 & 0.133 & 1.166 & 0.318 & 1.432 & 0.234 \\
\hline 基径 Basal stem & 0.004 & 0.996 & 0.612 & 0.545 & 0.211 & 0.931 \\
\hline 盆总生物量 * Total biomass per pot & 0.032 & 0.968 & 5.820 & 0.005 & 1.046 & 0.391 \\
\hline 单株地上生物量 * Aboveground biomass & 0.585 & 0.560 & 30.669 & $<0.001$ & 0.194 & 0.940 \\
\hline 单株地下生物量 * Underground biomass & 0.882 & 0.419 & 28.197 & $<0.001$ & 0.286 & 0.886 \\
\hline 单株生物量 ${ }^{*}$ Individual biomass & 0.727 & 0.488 & 29.653 & $<0.001$ & 0.239 & 0.915 \\
\hline 根冠比* Root-shoot ratio & 1.204 & 0.307 & 1.191 & 0.311 & 0.465 & 0.761 \\
\hline
\end{tabular}

* 表示数据经过对数变换
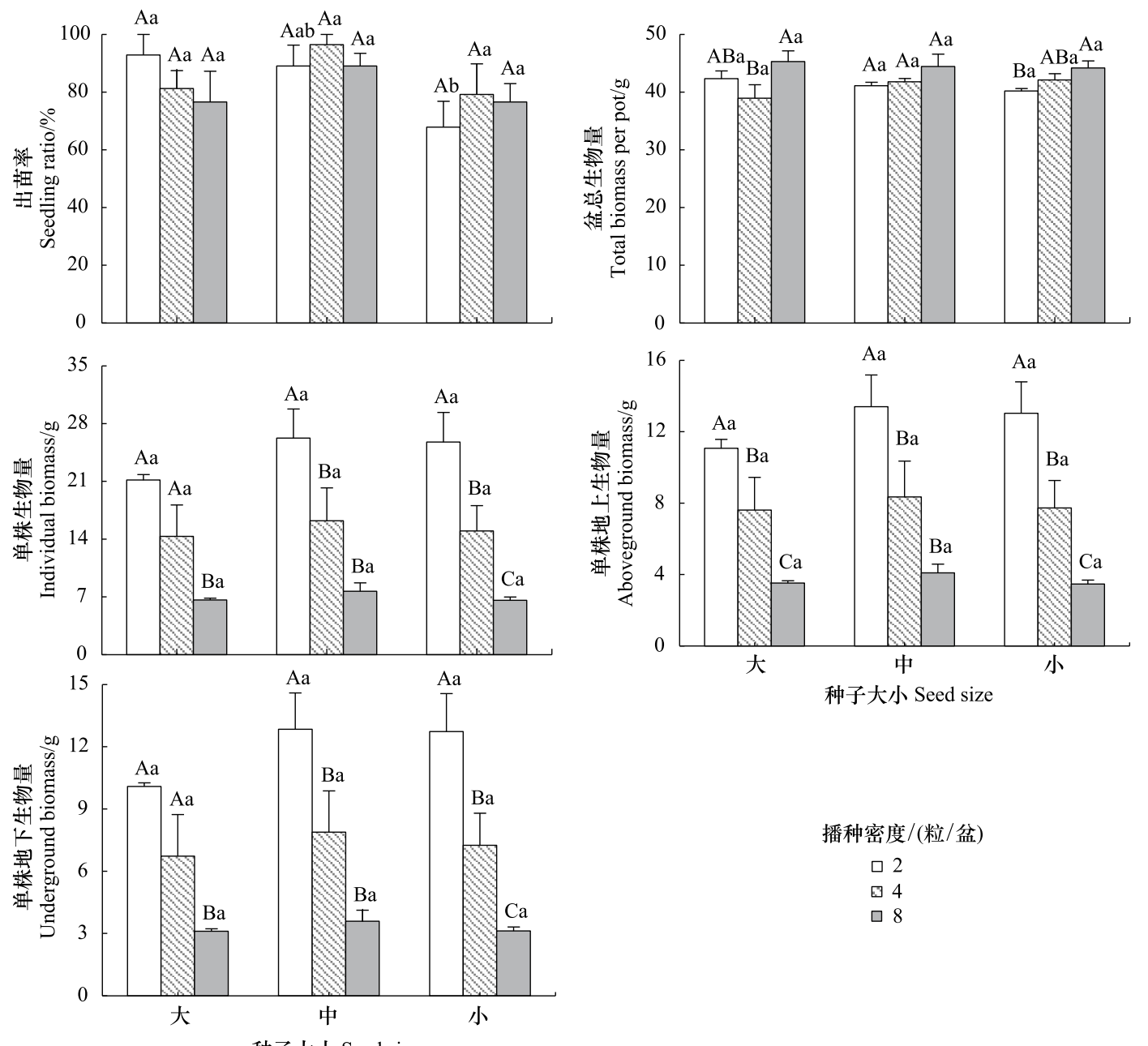

种子大小 Seed size

播种密度/(粒/盆)

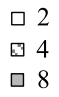

$\square$
$\square$

$\square 8$

图 2 不同种子大小在不同播种密度处理下各指标的差异

Fig.2 The difference of parameters among different seed size of $A$. artemisiifolia with different planting density 不同大写字母和不同小写字母分别表示同一大小种子的不同播种密度间以及同一播种密度下不同大小种子间差异显著 $(P<0.05)$

\section{3 讨论}

3.1 种子大小和埋深/播种密度对种子出苗的影响

大量研究表明种子大小对出苗有着显著影响 ${ }^{[2,12,35-36]}$,一般而言, 大种子具有更多的能量以支撑种子萌 
发后出苗,而较小的种子更可能在萌发后, 因无法到达土壤表面而死亡 ${ }^{[37]}$ 。但本研究中, 种子大小对出苗率 无显著影响, 可能是由于埋深实验中选择的豚草种子大小等级差异较小,使得种子大小之间的差异不能明显 地表现出来, 今后实验应加大豚草种子大小的分级差异。本研究发现播种深度对豚草种子的出苗率存在极显 著影响, 从埋深 $2 \mathrm{~cm}$ 时的 47.8\%-52.2\%下降到埋深 $6 \mathrm{~cm}$ 时的 4.4\%-13.3\%。前人的研究也证实了豚草种 子的出苗率随埋深的增加而减少这一趋势 ${ }^{[38-39]}$ 。因为播种的深度会影响种子周围的水分、光照、温度以及氧 气含量等环境因素, 埋深越深, 不宜的环境会抑制种子的萌发和出苗, 且出苗前死亡率也随之升高 ${ }^{[40-42]}$ 。对 其他人侵植物, 如白花鬼针草 (Bidens alba)、假臭草 (Praxelis clematidea) 和胜红蓟 (Ageratum conyzoides) ${ }^{[43]}$ 等 $^{-}$ 的研究均证实了埋深的增加会抑制种子的萌发和出苗。因此,通过深耕等方式将种子深埋人土,降低豚草的 出苗率, 从而达到一定的防除效果。

另一方面, 本研究还发现播种密度对豚草种子出苗率的影响不显著, 这说明豚草的出苗不受播种密度的 影响,无论在何种密度下,豚草的出苗率均能达到较高水平,这有利于它在不同生境中的传播和扩散,形成较 高竞争力, 这是人侵植物的一大特征 ${ }^{[4]}$ 。此外, 密度实验中, 种子大小对豚草的出苗率影响显著, 且总体上中 种子的出苗率较高, 与埋深实验结果的不同可能是因为两个实验中, 豚草种子的大小等级差异较小, 加之埋深 和播种密度条件不同造成的误差。

\section{2 种子大小和埋深/播种密度对幼苗形态特征的影响}

种子大小可以影响早期幼苗的建成, 从而影响植物在异质生境中的定殖 ${ }^{[11,45]}$ 。本研究发现埋深处理下, 种子大小显著影响豚草幼苗的株高和基径,整体上较大种子产生的幼苗的株高和基径高于小种子。这是由于 较大的种子由于储存的营养物种更多, 资源获取比小种子更有优势, 更有利于幼苗的生长。许多其他研究结 果也与本研究结果相同, 例如 $\mathrm{Mao}$ 等 ${ }^{[9]}$ 对中国山东半岛北部沿海外来植物日本黑松 (Pinus thunbergii Parl.) 种 子发芽和幼苗早期生长的研究发现, 大种子和中种子的幼苗高度和基径均高于小种子, 即较大的种子比小种 子在生长中更有优势。而播种密度处理中, 株高、根长、基径均不受种子大小的影响, 这可能是因为播种密度 实验中种子埋深较浅,削弱了种子大小的影响。

播种埋深影响幼苗光照及养分等营养物质的摄取, 从而影响幼苗的生长。本研究发现豚草幼苗的株高和 基径受埋深影响显著,且在浅埋深下最大,但仅小种子的株高和基径在不同埋深下的差异达到显著水平。这 可能是由于在较深的播种深度下, 种子将分配更多的能量用于萌发和出苗,而用于幼苗早期生长的能量减少, 同时埋深更深的种子所需的出苗的时间更长, 从而导致出土后的生长期缩短, 使得幼苗生长受限, 并且小种子 更易受埋深的影响 ${ }^{[38,46]}$ 。对辽东栋 ( Quercus wutaishanica) ${ }^{[11]}$ 、黑松 (Pinus thunbergii Parl.) ( $^{[9]}$ 、泡泡刺 (Nitraria sphaerocarpa $)^{[12]}$ 等的研究, 同样也证实了较浅的埋深下幼苗的株高更大。另一方面, 豚草幼苗的株 高、根长、基径受播种密度的影响不显著。说明播种密度对豚草早期幼苗的生长影响不大,因此它能够在不同 密度环境下生长定殖, 促进其在异质生境中的成功人侵。

3.3 种子大小和埋深/播种密度对幼苗生物量的影响

在两个实验中,种子大小对每盆总生物量、单株总生物量、单株地上生物量和单株地下生物量的影响均未 达到显著水平, 而埋深和播种密度对以上 4 个指标均具有极显著影响, 表明埋深和播种密度对豚草幼苗生物 量的影响大于种子大小的影响。种子大小对根冠比的影响仅在埋深 $4 \mathrm{~cm}$ 时达到显著水平, 且根冠比随种子 大小的增加而显著下降,说明更小的种子会将生物量更多的分配给根以促进幼苗的生长。

随埋深增加, 豚草幼苗的单株总生物量、单株地上和地下生物量均呈显著增加趋势, 而每盆总生物量在不 同埋深下无显著差异。埋深对豚草幼苗生物量的促进关系可能是由于较深的埋深更有利于根获取土壤养分 促进地下部分的生长, 吸收的养分运送到地上部分进而促进了茎和叶的生长。虽然豚草幼苗的单株生物量随 埋深增加而增加, 但是越深的播种深度意味着越低的出苗率, 因此每盆总生物量在不同埋深间差异不大。豚 草幼苗的根冠比在较深埋深下更大, 表明较深的埋深更有利于根的生长, 豚草幼苗将更多的能量分配给地下 部分, 从而导致根冠比的增加, 这与徐玲玲等 ${ }^{[47]}$ 对枫杨 (Pterocarya stenoptera) 种子的研究结果相似, 这是植物 
体应对埋深的一种生态适应 ${ }^{[48]}$, 且这种影响在小种子中表现更为明显。豚草的这种通过调整生物量分配以 适应不同埋深环境的策略,促进了其在不同生境中的人侵。

播种密度会影响幼苗的种内竞争,密度越高,水分、营养等资源的竞争越激烈, 同时幼苗叶片相互遮挡,影 响光照的获取, 从而影响光合作用, 抑制幼苗的生长 ${ }^{[15,49]}$ 。本实验中, 豚草幼苗的单株总生物量、单株地上和 地下生物量均随播种密度的增加而显著减少, 而每盆总生物量总体上随播种密度增加而呈上升趋势。随播种 密度的增加, 由于土壤营养物质有限, 幼苗为了获取养分而产生激烈的竞争, 从而导致单株幼苗的生长受限, 生物量积累受到抑制。Leskovšek 等 ${ }^{[29]}$ 的研究也与本研究结果一致, 即播种密度对豚草生物量积累具有负效 应。但是播种密度对每盆总生物量的促进作用表明高密度不会抑制豚草种群的整体生长。在野外, 人侵植物 豚草通常会形成高密度的单优群落, 阻碍其他本地植物的生长, 这可能是豚草成功人侵的原因之一。由于竞 争可以抑制豚草的生长, 因此可以选择竞争能力强的本地植物, 与豚草进行养分和光能等资源的竞争, 使得本 地种获得更大的生物量, 使人侵植物豚草处于不利地位。这种替代控制方法是抵御外来杂草人侵扩张的有效 途径之一 ${ }^{[50]}$ 。

综上所述, 种子大小对豚草出苗和生长的影响均较小,但总体上较大的种子的生长比较小的种子更具有 优势。本研究中豚草种子大小的分级差异较小, 可能导致了种子大小的影响效应不明显, 因此今后研究中应 加大种子大小的分级差异。豚草种子的出苗主要受到埋深的影响, 较浅的埋深更有利于豚草种子的出苗; 不 同播种密度下, 豚草种子的出苗率均较高, 达到 67.9\%-100\%, 有利于它在不同生境中的传播和扩散。豚草 幼苗生长受埋深和播种密度影响更大, 且小种子更易受埋深和播种密度的影响。浅层埋深幼苗的株高和基径 更大, 埋深对豚草幼苗生物量具有促进作用。播种密度会影响豚草幼苗的种内竞争, 抑制其生物量积累。由 此可见, 豚草在浅层埋深处理下能够保持较高的出苗率, 拥有较大的株高和基径; 播种密度较小的条件下, 豚 草植株生物量更大, 即豚草在浅埋深、低密度生境中更容易人侵成功。因此, 为有效管理和防治豚草, 应在春 耕前对土壤进行深翻, 增加种子的埋深, 减少豚草的出苗率; 还可以采取替代控制, 种植竞争能力强的本地植 物, 抑制豚草的生长和扩散。

\section{参考文献 (References) :}

[ 1 ] Vilà M, Espinar J L, Hejda M, Hulme P E, Jarošík V, Maron J L, Pergl J, Schaffner U, Sun Y, Pyšek P. Ecological impacts of invasive alien plants: a meta-analysis of their effects on species, communities and ecosystems. Ecology Letters, 2011, 14(7) : 702-708.

[ 2 ] 武高林, 杜国祯. 植物种子大小与幼苗生长策略研究进展. 应用生态学报, 2008, 19(1): 191-197.

[ 3 ] 何影, 马沝. 入侵植物意大利苍耳种子萌发对环境因子的响应. 生态学报, 2018, 38(4) : 1226- 1234.

[ 4 ] 胡宗英, 孙泽威. 影响农牧作物种子萌发的因素. 安徽农业科学, 2013, 41(32): 12537-12538.

[ 5 ] Westoby M, Jurado E, Leishman M. Comparative evolutionary ecology of seed size. Trends in Ecology \& Evolution, 1992, 7(11): 368-372.

[ 6 ] Silvertown J W. Seed size, life span, and germination date as coadapted features of plant life history. The American Naturalist, 1981, 118(6): 860-864.

[ 7 ] Harper J L, Lovell P H, Moore K G. The shapes and sizes of seeds. Annual Review of Ecology and Systematics, 1970, 1: $327-356$.

[ 8 ] Harrison S K, Regnier E E, Schmoll J T, Harrison J M. Seed size and burial effects on giant ragweed (Ambrosia trifida) mergence and seed demise. Weed Science, 2007, 55(1): 16-22.

[ 9 ] Mao P L, Guo L M, Gao Y X, Qi L, Cao B H. Effects of seed size and sand burial on germination and early growth of seedlings for coastal Pinus thunbergii Parl. in the northern Shandong Peninsula, China. Forests, 2019, 10(3) : 281.

[10] Harper J L, Benton R A. The Behaviour of Seeds in Soil: II. The germination of seeds on the surface of a water supplying substrate. Journal of Ecology, 1966, 54(1) : 151-166.

[11] 张金峰, 程继铭, 间兴富, 罗永红, 朱雅婷. 种子特征和播种深度对辽东栋种子萌发和幼苗生长的影响. 广西植物, 2020, 40(2)： 226- 236 .

[12] Li Q Y, Zhao W Z, Fang H Y. Effects of sand burial depth and seed mass on seedling emergence and growth of Nitraria sphaerocarpa. Plant Ecology, 2006, 185(2): 191-198.

[13] Chen H, Maun M A. Effects of sand burial depth on seed germination and seedling emergence of Cirsium pitcheri. Plant Ecology, 1999, 140(1): 53-60.

[14] 黎否, 周道玮, 盛连喜. 密度制约决定的植物生物量分配格局. 生态学杂志, 2011, 30(8) : 1579-1589.

[15］李博, 陈家宽, 沃金森 A R. 植物竞争研究进展. 植物学通报, 1998, 15(4) : 18-29.

[16] Holle B V, Simberloff D. Ecological resistance to biological invasion overwhelmed by propagule pressure. Ecology, 2005, 86( 12) : 3212-3218.

[17] Silveira M J, Alves D C, Thomaz S M. Effects of the density of the invasive macrophyte Hydrilla verticillata and root competition on growth of one 
native macrophyte in different sediment fertilities. Ecological Research, 2018, 33(5): 927-934.

[18］刘静玲, 冯树丹, 慕颖. 豚草生态学特性及生防对策. 东北师大学报: 自然科学版, 1997, (3): 61-67.

[19] Essl F, Dullinger S, Kleinbauer I. Changes in the spatio-temporal patterns and habitat preferences of Ambrosia artemisiifolia during its invasion of Austria. Preslia, 2009, 81(2): 119-133.

［20］全国明, 刘荣莹, 毛丹鹃, 章家恩, 谢俊芳. 降雨量变化对人侵植物豚草植株生长的影响. 生态科学, 2018, 37(2): 138-146.

[21] Smith M, Cecchi L, Skjøth C A, Karrer G, Šikoparija B. Common ragweed: a threat to environmental health in Europe. Environment International, 2013, 61: 115- 126.

[22] Hodgins K A, Rieseberg L. Genetic differentiation in life-history traits of introduced and native common ragweed (Ambrosia artemisiifolia) populations. Journal of Evolutionary Biology, 2011, 24(12): 2731-2749.

[23] 邓贞贞, 白加德, 赵彩云, 李俊生. 外来植物豚草人侵机制. 草业科学, 2015, 32(1): 54-63.

[24] Li X M, She D Y, Zhang D Y, Liao W J. Life history trait differentiation and local adaptation in invasive populations of Ambrosia artemisiifolia in China. Oecologia, 2015, 177(3): 669-677.

[25] Sun Y, Roderick G K. Rapid evolution of invasive traits facilitates the invasion of common ragweed, Ambrosia artemisiifolia. Journal of Ecology, $2019,107(6): 2673-2687$.

[26] Lavoie C, Jodoin Y, De Merlis A G. How did common ragweed (Ambrosia artemisiifolia L.) spread in Québec? A historical analysis using herbarium records. Journal of Biogeography, 2007, 34(10): 1751-1761.

［27］董合干, 周明冬, 刘忠权, 郝晓云, 刘延, 艾尼瓦尔・阿不都瓦依提, 刘形. 豚草和三裂叶豚草在新疆伊犁河谷的人侵及扩散特征. 干旱 区资源与环境, 2017, 31(11): 175-180.

[28] Afonin A N, Fedorova Y A, Li Y S. Characterization of the occurrence and abundance of the common ragweed (Ambrosia artemisiifolia L.) with regard to assessment of its expansion potential in European Russia. Russian Journal of Biological Invasions, 2019, 10(3) : 220-226.

[29] Leskovšek R, Datta A, Simoncic A, Knezevic S Z. Influence of nitrogen and plant density on the growth and seed production of common ragweed (Ambrosia artemisiifolia L.). Journal of Pest Science, 2012, 85(4) : 527-539.

[30] Gentili R, Ambrosini R, Montagnani C, Caronni S, Citterio S. Effect of soil pH on the growth, reproductive investment and pollen allergenicity of Ambrosia artemisiifolia L. Frontiers in Plant Science, 2018, 9: 1335.

[31] Skálová H. Performance of Ambrosia artemisiifolia and its potential competitors in an experimental temperature and salinity gradient and implications for management. Management of Biological Invasions, 2019, 10(2): 359-376.

[32] 孙燕, 周忠实, 王瑞, Müller-Schärer H. 气候变化预计会减少东亚地区豚草的生物防治效果. 生物多样性, 2017, 25(12): 1285-1294.

[33] Green P T, O'Dowd D J, Lake P S. Control of seedling recruitment by land crabs in rain forest on a remote oceanic island. Ecology, 1997, 78( 8) : 2474-2486.

[34] 邓贞贞, 赵相健, 赵彩云, 李俊生. 繁殖体压力对豚草 (Ambrosia artemisiifolia) 定殖和种群维持的影响. 生态学杂志, 2016, 35(6)： 1511-1515.

[35] Sadeghi H, Khazaei F, Sheidaei S, Yari L. Effect of seed size on seed germination behavior of safflower (Carthamus tinctorius L.). ARPN Journal of Agricultural and Biological Science, 2011, 6(4): 5-8.

[36] Pearson T R H, Burslem D F R P, Mullins C E, Dalling J W. Germination ecology of neotropical pioneers: interacting effects of environmental conditions and seed size. Ecology, 2002, 83(10): 2798-2807.

[37] 朱雅娟, 董鸣, 黄振英. 沙埋和种子大小对固沙禾草沙鞭的种子萌发与幼苗出土的影响. 植物生态学报, 2005, 29(5): 730-739.

[38] Guillemin J P, Chauvel B. Effects of the seed weight and burial depth on the seed behavior of common ragweed (Ambrosia artemisiifolia). Weed Biology and Management, 2011, 11(4): 217-223.

[39] Essl F, Biró K, Brandes D, Broennimann O, Bullock J M, Chapman D S, Chauvel B, Dullinger S, Fumanal B, Guisan A, Karrer G, Kazinczi G, Kueffer C, Laitung B, Lavoie C, Leitner M, Mang T, Moser D, Müller-Schärer H, Petitpierre B, Richter R, Schaffner U, Smith M, Starfinger U, Vautard R, Vogl G, von der Lippe M, Follak S. Biological flora of the British Isles: Ambrosia artemisiifolia. Journal of Ecology, 2015, 103 (4) : 1069-1098.

[40] Huang Z Y, Gutterman Y. Artemisia monosperma achene germination in sand: effects of sand depth, sand/water content, cyanobacterial sand crust and temperature. Journal of Arid Environments, 1998, 38(1): 27-43.

[41] Vleeshouwers L M. Modelling the effect of temperature, soil penetration resistance, burial depth and seed weight on pre-emergence growth of weeds. Annals of Botany, 1997, 79(5): 553-563.

[42] Jørgensen M S, Labouriau R, Olesen B. Seed size and burial depth influence Zostera marina L. (eelgrass) seed survival, seedling emergence and initial seedling biomass development. PLoS One, 2019, 14(4): e0215157.

[43] 钟军弟, 周贤熙, 李晓琳, 袁长春, 刘金祥, 刘晚荷. 不同埋藏深度对白花鬼针草、假臭草和胜红蓟种子出苗及生长的影响. 热带农业科 学, 2017, 37(1): 1-6.

[44] van Kleunen M, Johnson S D. South African Iridaceae with rapid and profuse seedling emergence are more likely to become naturalized in other regions. Journal of Ecology, 2007, 95(4): 674-681.

[45] 何彦龙, 王满堂, 杜国祯. 不同光照处理下青藏高原克隆植物黄帚㯻吾 (Ligularia virgaurea) 种子大小对其幼苗生长的影响. 生态学报, 2007, 27(8): 3091-3098.

[46] Seiwa K, Watanabe A, Saitoh T, Kannu H, Akasaka S. Effects of burying depth and seed size on seedling establishment of Japanese chestnuts, Castanea crenata. Forest Ecology and Management, 2002, 164(1/3): 149-156.

[47] 徐玲玲, 雷耘, 汪正祥. 枫杨种子和幼苗对地下水位及埋藏深度的响应. 生态与农村环境学报, 2013, 29(1): 49-52.

[48] 陈文, 王桔红, 张勇, 强晓霞. 沙埋对花棒种子萌发和幼苗生长的影响. 生态科学, 2011, 30(1): 26-31.

[49] 李博, 杨持, 林鹏. 生态学. 北京: 高等教育出版社, 2000.

[50］高尚宾, 张宏斌, 孙玉芳, 张国良. 植物替代控制 3 种人侵杂草技术的研究与应用进展. 生物安全学报, 2017, 26(1)：18-22, 102-102. 